Article

\title{
Development of Environmentally Friendly Cellulose Derivative-Based Hydrogels for Contact Lenses Using a Radiation Crosslinking Technique
}

\author{
Akihiro Hiroki * and Mitsumasa Taguchi $\mathbb{D}$ \\ Quantum Beam Science Research Directorate, National Institutes for Quantum and Radiological Science and \\ Technology (QST), Takasaki 370-1292, Japan; taguchi.mitsumasa@qst.go.jp \\ * Correspondence: hiroki.akihiro@qst.go.jp
}

check for

updates

Citation: Hiroki, A.; Taguchi, M. Development of Environmentally Friendly Cellulose Derivative-Based Hydrogels for Contact Lenses Using a Radiation Crosslinking Technique. Appl. Sci. 2021, 11, 9168. https:// doi.org/10.3390/app11199168

Academic Editors:

Dorota Swiatla-Wojcik,

Yosuke Katsumura and Radosław A. Wach

Received: 31 August 2021

Accepted: 29 September 2021

Published: 2 October 2021

Publisher's Note: MDPI stays neutral with regard to jurisdictional claims in published maps and institutional affiliations.

Copyright: (c) 2021 by the authors. Licensee MDPI, Basel, Switzerland. This article is an open access article distributed under the terms and conditions of the Creative Commons Attribution (CC BY) license (https:// creativecommons.org/licenses/by/ $4.0 /)$.

\begin{abstract}
Although they have potential environmental pollution issues, soft contact lenses are value-added biodevices for medical use. Thus, it is important to reconsider starting materials and production methods to achieve sustainable development. In this study, hydrogels composed of hydroxypropyl cellulose (HPC) as an environmentally friendly material were produced by radiation and investigated for use in disposable soft contact lenses. HPC-based hydrogels with good mechanical properties and transparency were prepared by irradiation of electron beams on highly concentrated aqueous solutions containing HPC, polyethylene glycol \#1000 dimethacrylate (23G), and 2-hydroxyethyl methacrylate (HEMA). The addition of 23G to HPC aqueous solutions resulted in an increase in the gel fraction as well as improved mechanical properties, such as tensile strength and elongation at break. The tensile strength and the elongation at break of HPC/HEMA/23G hydrogel obtained by the further addition of HEMA with HPC/23G aqueous solutions exhibited 0.2 MPa and $124 \%$, which were approximately 2.0 and 1.8 times larger than these of the pure HPC hydrogel, respectively. The evaluation of the properties of the HPC/HEMA/23G hydrogel demonstrated its potential as a soft contact material with improved mechanical properties.
\end{abstract}

Keywords: hydrogel; soft contact lens; radiation; crosslinking; hydroxypropyl cellulose

\section{Introduction}

Recent studies have focused on the contamination of aquatic and terrestrial environments because of disposable soft contact lenses [1,2]. Studies show that approximately $80 \%$ of soft contact lens wearers use disposable contact lenses. It was found that approximately $80 \%$ of the used disposable contact lenses are thrown away in the trash, and approximately $20 \%$ are washed away in kitchen drains and toilets. Contact lenses do not entirely decompose in sewage treatment plants because of their low biodegradability. The generated sludge, including undecomposed contact lenses, causes microplastic pollution because it is disposed of in coastal waters or used in agricultural soils.

Silicone-based hydrogels are the most common soft contact lens material, accounting for approximately $64 \%$ of the US market [3]. Because of their porous nature, silicones have the highest oxygen permeability among all contact lens materials. Furthermore, silicone soft contact lenses are highly durable and have a higher modulus of elasticity than conventional polymer hydrogels. However, they have been reported not to degrade in chemical or biological treatments, although they physically break down and become smaller in sewage treatment plants.

Poly (2-hydroxyethyl methacrylate (pHEMA) has also been widely used as a material for commercial soft contact lenses [3-5]. pHEMA-based hydrogels are transparent and soft and have high oxygen permeability and, thus, have excellent properties related to corneal hypoxia. However, the adsorption of proteins is an issue for pHEMA hydrogels [6,7]. It has been reported that the charge and porosity (water content) of the gels affect the adsorption 
and permeation of proteins $[8,9]$. In addition, monomers, such as methyl methacrylate and $\mathrm{N}$-vinyl pyrrolidone, which are also used in commercially available contact lenses, have been reported to increase protein deposition.

With the objective of producing a sustainable society, the use of environmentally friendly plant-derived materials has recently attracted significant attention. A classic example is the use of plant-derived materials for disposable shopping bags and drinking straws that are used in significant quantities. Furthermore, polylactic acid trash bags made from corn and water-absorbent disposable diapers made from cellulose have been developed $[10,11]$. In addition, cellulose derivatives, which are potential water absorbents, are also used in medical materials, such as wound dressings and drug delivery systems [12,13]. However, no studies have been published on soft contact lens materials containing cellulose or cellulose derivatives as the primary components.

The irradiation effects of quantum beams such as electron beams and $\gamma$-rays on proteins, especially on the mechanism of a crosslinking reaction, have been investigated, and various materials for medical applications have been developed using such irradiation techniques. Protein hydrogels have been prepared as scaffolding materials for the threedimensional culture of cells [14] and contrast agents for magnetic resonance imaging diagnostics [15]. These hydrogels have also been used to produce cell sheets on which cells form three-dimensional structures by themselves [16] and materials for preventing organ adhesion after abdominal surgery [17].

Cellulose is the most abundant natural organic polymer on earth. Although cellulose has low solubility in water and most organic solvents, it can be chemically modified to make it highly functional, and hydrogel materials for use in biological and medical fields have been created [18]. Various hydrogels have been prepared using radiationcrosslinking cellulose derivatives [19-21]. Gel dosimeters for radiotherapy have been developed using a reaction in transparent hydroxypropyl cellulose (HPC) gels [22,23]. Based on these findings, we developed hydrogels for fabricating environmentally friendly soft contact lenses using radiation processing techniques. We investigated the effects of cellulose derivatives, the composition of monomers, and the effect on the transparency and mechanical properties of the hydrogels. Hydrogels for soft contact lenses comprised of HPC as the main component were prepared by crosslinking HPC and polymerization of methacrylate monomers simultaneously.

\section{Materials and Methods}

\subsection{Materials}

Methylcellulose (MC) (METLOSE ${ }^{\circledR}$, SM-1500) and hydroxypropyl methylcellulose (HPMC) (METOLOSE $\left.{ }^{\circledR}, 90 \mathrm{SH}-4000\right)$ were purchased from Shin-Etsu Chemical Co., Ltd. Tokyo, Japan. HPC, with a grade of 1000-5000 cP, and 2-hydroxyethyl methacrylate (HEMA) were purchased from FUJIFILM Wako Pure Chemical Corporation, Tokyo, Japan. Polyethylene glycol \#1000 dimethacrylate (23G) was supplied by Shin-Nakamura Chemical Co. Ltd., Wakayama, Japan. All the chemicals were used without further purification. Figure 1 shows the chemical structures of the methacrylate monomers.<smiles>C=C(C)C(=O)OCCO</smiles>

HEMA

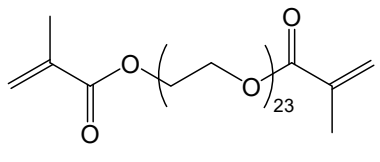

$23 G$

Figure 1. Chemical structures of HEMA and 23G.

\subsection{Preparation of Hydrogels}

MC, HPMC, and HPC were dissolved in ultrapure water at a concentration of $20 \mathrm{wt} . \%$. An aqueous solution with a paste-like texture was sandwiched between polyethylene terephthalate films of $50 \mu \mathrm{m}$ thickness and pressed to form a $150 \mathrm{~mm}$ long $\times 150 \mathrm{~mm}$ wide $\times 1 \mathrm{~mm}$ thick shape sealed in polyethylene-nylon packaging after degassing. Concentrated aqueous 
solutions containing HPC, HEMA, and 23G were prepared, in which HPC, HEMA, and 23G concentrations were $20 \mathrm{wt} . \%, 1.0-4.0 \mathrm{wt} . \%$, and $0.1-1.0 \mathrm{wt} . \%$, respectively. The concentrated aqueous solution was sandwiched between $25 \mu \mathrm{m}$ thick polyethylene terephthalate films and pressed to form a $150 \mathrm{~mm}$ long $\times 150 \mathrm{~mm}$ wide $\times 100 \mu \mathrm{m}$ thick shape and then sealed in polyethylene-nylon packaging after degassing. The samples were irradiated at a dose of $10-50 \mathrm{kGy}(\mathrm{Gy}=\mathrm{J} / \mathrm{kg})$ at a dose rate of $10 \mathrm{kGy} /$ pass to obtain gels. The irradiations were carried out using a Cockcroft-Walton type electron beam accelerator $(2 \mathrm{MeV}, 2 \mathrm{~mA})$ at the Takasaki Advanced Radiation Research Institute, QST.

\subsection{Gel Fraction and Swelling of Hydrogels}

The obtained gels were vacuum-dried at $30{ }^{\circ} \mathrm{C}$ for $24 \mathrm{~h}$. The dried sample was immersed in an excess amount of distilled deionized water at $25^{\circ} \mathrm{C}$ for $48 \mathrm{~h}$ to remove the uncrosslinked polymer and homopolymer. The gel content in the sample was estimated by measuring the gravimetrically insoluble parts after extraction in distilled deionized water. The gel fraction of the gels was calculated using the following Equation:

$$
\text { Gel fraction }(\%)=W_{1} / W_{0} \times 100 \text {, }
$$

where $W_{1}$ is the weight of the dry gel after extraction, and $W_{0}$ is the initial weight of the dry gel.

The obtained gels were immersed in distilled deionized water for $48 \mathrm{~h}$ at $25^{\circ} \mathrm{C}$. After wiping the excess water off the surface of the gel, the weight of the swollen gel was measured. The degree of swelling $(\mathrm{Sw})$ of the gels was calculated using the following Equation:

$$
\mathrm{Sw}=\left(\mathrm{W}_{\mathrm{s}}-\mathrm{W}_{\mathrm{d}}\right) / \mathrm{W}_{\mathrm{d}},
$$

where $W_{s}$ is the weight of the swollen gel and $W_{d}$ is the weight of the dried gel.

\subsection{Transparency}

The transparency of the swollen MC, HPMC, and HPC gels after extraction was measured using a spectrophotometer (U-3310, Hitachi High-Technology Corporation, Tokyo, Japan).

\subsection{Fourier Transform Infrared (FT-IR) Spectra of Gels}

FT-IR attenuated total reflection (ATR) spectra of the gels were measured using IRAffinity-1S (Shimadzu Corporation, Kyoto, Japan) with an ATR accessory (DuraSamplIR II, Smiths, Tokyo, Japan).

\subsection{Mechanical Properties}

The mechanical properties of the obtained gels were measured using a Table-Top Material Tester EZ Test EZ-L (Shimadzu Corporation, Kyoto, Japan). The tensile strength and elongation at break were measured by expanding the swollen gels cut into strip specimens ( $30 \mathrm{~mm}$ long $\times 5 \mathrm{~mm}$ wide) at a $30 \mathrm{~mm} / \mathrm{min}$ crosshead speed. At least five measurements were recorded for each sample, and the mean values were calculated. Young's modulus, as an indicator of the elasticity of the hydrogels, was then determined from the slope of the stress-strain curves in the strain range from $0 \%$ to $10 \%$.

\section{Results and Discussion}

\subsection{Hydrogel Production}

When a mixture of polysaccharide derivatives and water is irradiated with quantum beams, such as electron beams and $\gamma$-rays, decomposition and crosslinking reactions of polysaccharide derivatives occur simultaneously [19]. At a low concentration of polysaccharide derivatives, the decomposition reaction of polysaccharide derivatives occurred predominantly compared to the crosslinking reaction. At a high concentration of more than $10 \mathrm{wt} . \%$, the crosslinking reaction dominated over the decomposition and resulted in a gel. 
The hydrogels obtained by irradiating concentrated aqueous solutions of carboxymethyl cellulose or carboxymethyl chitosan are highly water-absorbent and transparent. However, metal ions and proteins are easily attached to the hydrogels [24]. Therefore, in this study, non-ionic MC, HPMC, and HPC were selected because of the objective of developing soft contact lenses that proteins do not readily adhere to. Figure 2a shows the relationship between the dose and gel fraction of the hydrogels obtained by irradiation with $20 \mathrm{wt} . \%$ aqueous solutions of MC, HPMC, and HPC. To select a base material for contact lenses, we prepared MC, HPMC, and HPC hydrogels with a thickness of $1 \mathrm{~mm}$, which is easy to handle. The gel fractions of the MC, HPMC, and HPC hydrogels increased substantially up to $10 \mathrm{kGy}$ and then leveled off at approximately $30 \mathrm{kGy}$ to reach approximately $80 \%$ at $50 \mathrm{kGy}$. The gel fractions at $10 \mathrm{kGy}$ increased in the order of HPMC, MC, and HPC. This indicates that HPC is the easiest to crosslink. Figure $2 b$ shows the relationship between the dose and Sw of the MC, HPMC, and HPC hydrogels. The Sw of the hydrogels decreased gradually with increasing dose, and HPC gels exhibited the lowest swelling profile. Although the gel fraction was almost the same (approximately 80\%), Sw decreased with increasing dose. This indicates that, as the crosslinking reaction progressed, the crosslinking density increased.

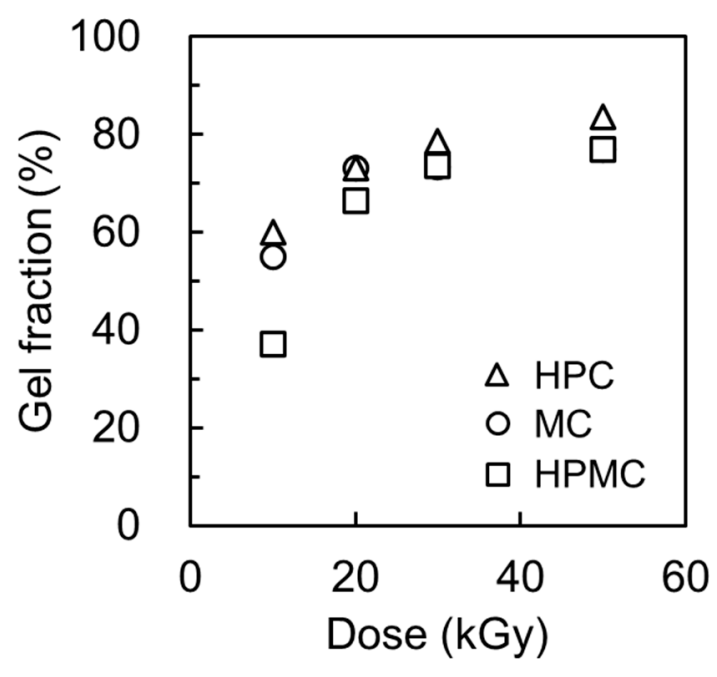

(a)

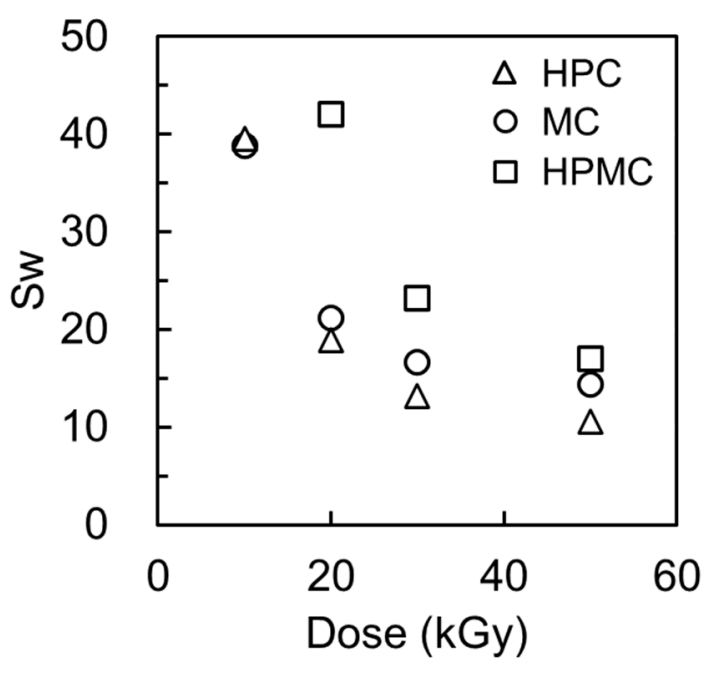

(b)

Figure 2. (a) Gel fraction and (b) Sw of MC, HPMC, and HPC hydrogels as a function of dose.

\subsection{Transparency}

The transparency of the hydrogel is a critical property for its use as a contact lens material. MC, HPMC, and HPC hydrogels with almost the same Sw (22-23) were selected, and the transmittance in the visible light region was measured. As shown in Figure 3, the transmittance of the hydrogels increased in the following order: MC, HPMC, and HPC. The HPC hydrogel was found to be the best material for use in soft contact lenses. Furthermore, appropriate mechanical properties are required for contact lens materials because they are handled manually by the user. The mechanical property test results showed that the tensile strength and elongation at break of the HPC hydrogel obtained at $50 \mathrm{kGy}$ were $0.1 \mathrm{MPa}$ and $70 \%$, respectively. It was found that the HPC hydrogel had low elongation and was easy to split. Therefore, the mechanical properties of HPC gel were improved. 


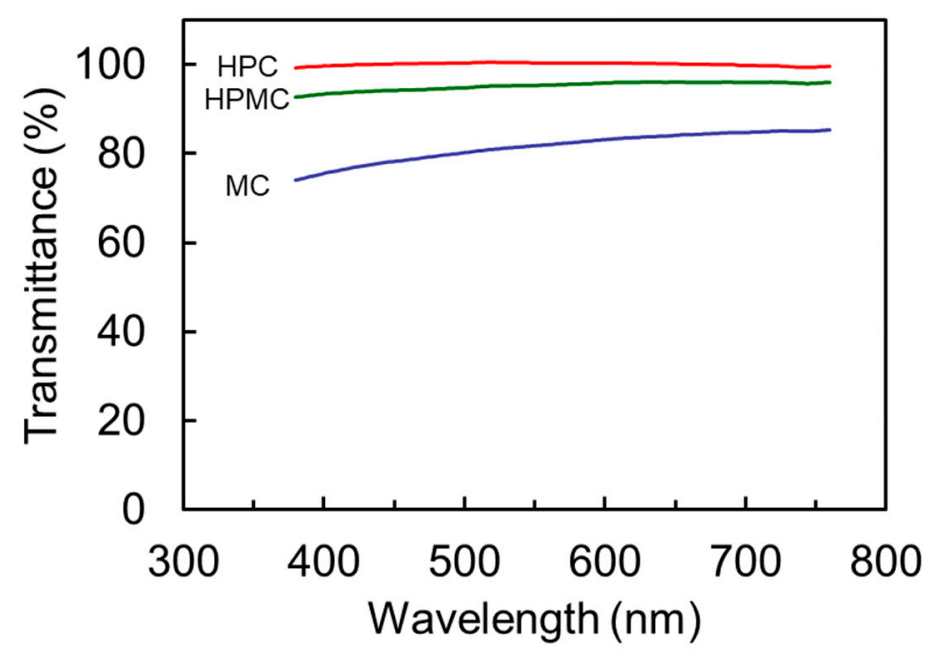

Figure 3. UV—-vis spectra of MC, HPMC, and HPC hydrogels in the visible light region.

\subsection{HPC/23G Hydrogel}

The formation of a double network structure and a nanocomposite with clay has been reported to increase the strength of polymer gels [25,26]. Another study reported a blend of two types of polymers to improve the properties of hydrogels [27]. The blend gel obtained by irradiation of a mixed aqueous solution of the two polymers had different characteristics. Polyvinyl alcohol (PVA) was selected to improve the mechanical properties of HPC gel by blending with another polymer because the radiation-crosslinked PVA hydrogels exhibited high transparency and excellent mechanical properties and were used in wound dressing materials [28]. The HPC/PVA blend hydrogel was prepared by electron beam irradiation of a blended aqueous solution of HPC and PVA as a preliminary experiment. However, the obtained HPC/PVA hydrogels were semitransparent owing to the microphase separation. Therefore, attempts were made to improve the mechanical properties by adding a water-soluble crosslinker based on polyethylene glycol to the HPC aqueous solution and crosslinking. Figure 4 a shows the gel fraction of the hydrogels prepared from a mixed aqueous solution of HPC and 23G. HPC/23G hydrogels with a thickness of $100 \mu \mathrm{m}$, close to commercially available contact lenses, were prepared. The gel fraction of the HPC/23G hydrogels was higher than that of the HPC hydrogels without $23 \mathrm{G}$, especially at low doses. The gel fraction of the HPC/23G (20/0.2) hydrogel reached $80 \%$ at $20 \mathrm{kGy}$. This indicates that the addition of the crosslinker 23G accelerated the gelation and crosslinking reactions of HPC. At the same dose, the gel fraction increased at a higher concentration of 23G. The difference in the gel fraction was remarkable at $10 \mathrm{kGy}$. At $50 \mathrm{kGy}$, there was no effect of the concentration of $23 \mathrm{G}$ on the gel fraction. It has been reported that the radicals on the side groups of cellulose derivatives generated by irradiation participate in crosslinking reactions, leading to the formation of the gel [29]. In the presence of monomers, the generated polymer radical reacts more quickly with the monomer of low molecular weight than with the polymer radical to form the branched and crosslinked structures. Therefore, in the presence of $23 \mathrm{G}$ as the crosslinker, the gel fraction increased sharply, even at low doses. In contrast, the Sw of the HPC/23G hydrogels decreased with increasing dose, as shown in Figure $4 \mathrm{~b}$. At the same dose, the Sw of the $\mathrm{HPC} / 23 \mathrm{G}$ hydrogels decreased with an increasing concentration of 23G. This was due to an increase in crosslinking density. 


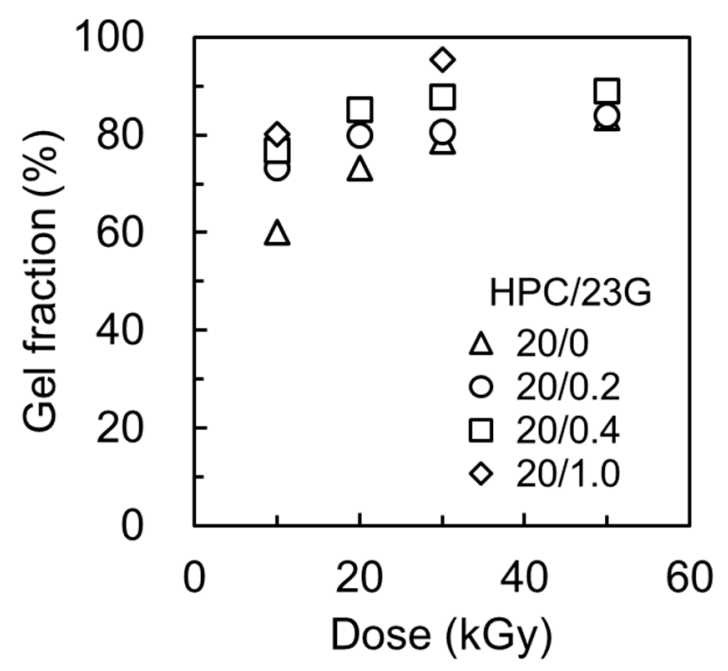

(a)

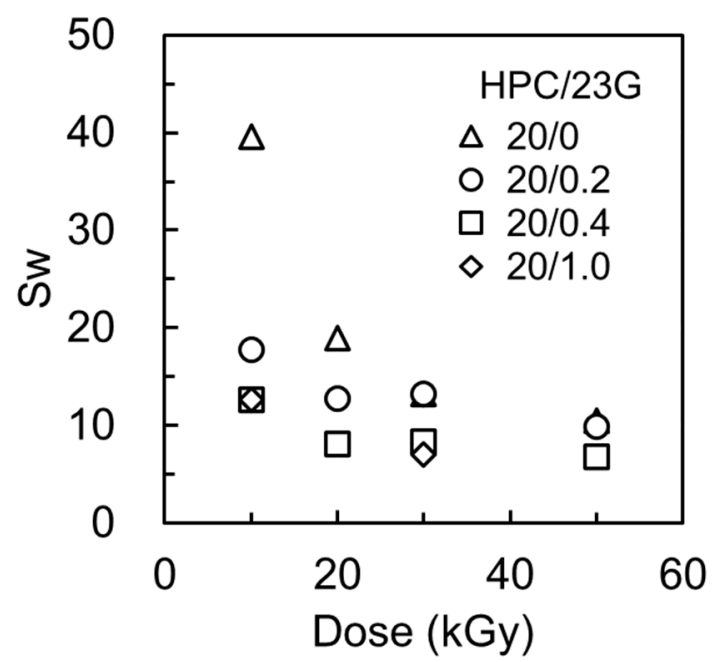

(b)

Figure 4. (a) Gel fraction and (b) Sw of HPC/23G hydrogels as a function of dose. The HPC/23G hydrogels were prepared by irradiation of the mixed aqueous solutions, in which the concentrations of HPC and $23 \mathrm{G}$ were $(\triangle)$ 20/0, $(\bigcirc)$ 20/0.2, ( $\square$ ) $20 / 0.4$, and $(\diamond) 20 / 1.0$ wt. $\% /$ wt. $\%$.

The tensile strength and elongation at break of the obtained HPC/23G hydrogels as a function of $23 \mathrm{G}$ concentration are shown in Figure $5 \mathrm{a}, \mathrm{b}$, respectively. The tensile strength of the HPC/23G hydrogel was a maximum at a 23G concentration of $0.2 \mathrm{wt} . \%$ and decreased with increasing concentration of the 23G at any dose. Accordingly, the HPC / 23G hydrogels became brittle and not easy to stretch because of an increase in the gel fraction and crosslinking density. Therefore, the optimum conditions for obtaining the HPC/23G hydrogel that exhibited a good balance between the tensile strength and elongation at break was a $23 \mathrm{G}$ concentration of $0.2 \mathrm{wt} . \%$ and at $30 \mathrm{kGy}$. As a result, the tensile strength and elongation at break of the HPC/23G hydrogel (20/0.2, $30 \mathrm{kGy})$ prepared under optimum conditions were higher, about 3.0 and 1.5 times, respectively, than those of the pure HPC hydrogel without 23G.

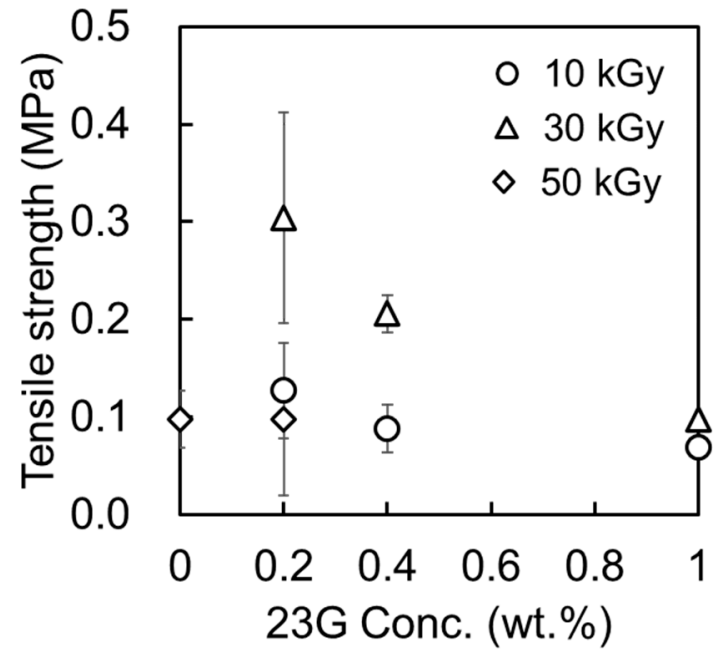

(a)

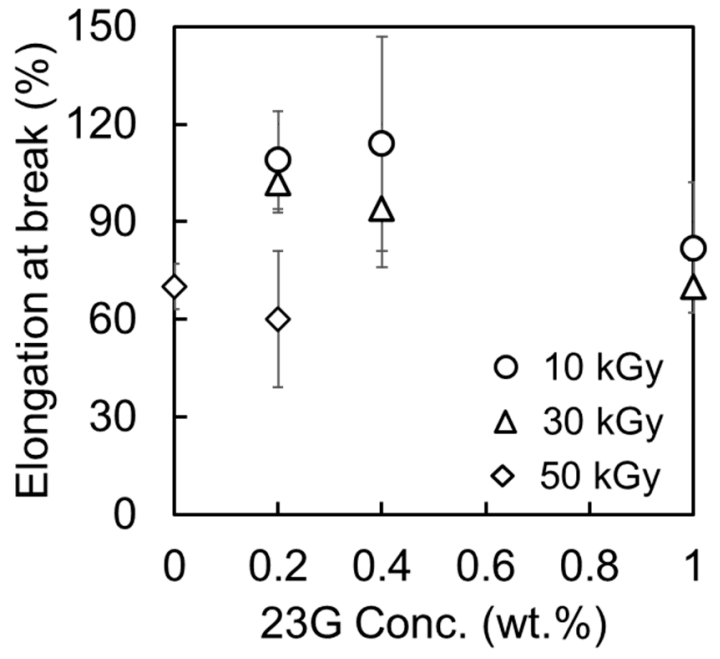

(b)

Figure 5. (a) Tensile strength and (b) elongation at break of HPC/23G hydrogels as a function of 23G concentration. The $\mathrm{HPC} / 23 \mathrm{G}$ hydrogels were prepared at $(\bigcirc) 10 \mathrm{kGy},(\triangle) 30 \mathrm{kGy}$, and $(\diamond) 50 \mathrm{kGy}$. 


\subsection{HPC/23G/HEMA Hydrogel}

To improve the tensile strength and elongation at break, the hydrogels were prepared by adding HEMA, a well-known base material for soft contact lenses. Figure $6 \mathrm{a}$,b show the gel fraction and Sw of the HPC/23G/HEMA hydrogels as a function of the dose, respectively. The gel fraction of the HPC/23G/HEMA hydrogels increased with increasing dose, as shown in Figure 6a. The substantial increase in the gel fraction shifted to the higher dose side with an increase in HEMA concentration. This suggested that HEMA inhibited the crosslinking reaction of HPC as the main component, especially in the low dose range. In contrast, the Sw of the HPC /23G/HEMA hydrogels decreased gradually with increasing concentrations. The Sw of the HPC/23G/HEMA hydrogels at greater than $30 \mathrm{kGy}$ was independent of the HEMA concentration and was almost the same. However, at 10 and $20 \mathrm{kGy}$, Sw increased with increasing concentration of HEMA because of the decrease in the crosslinking density.

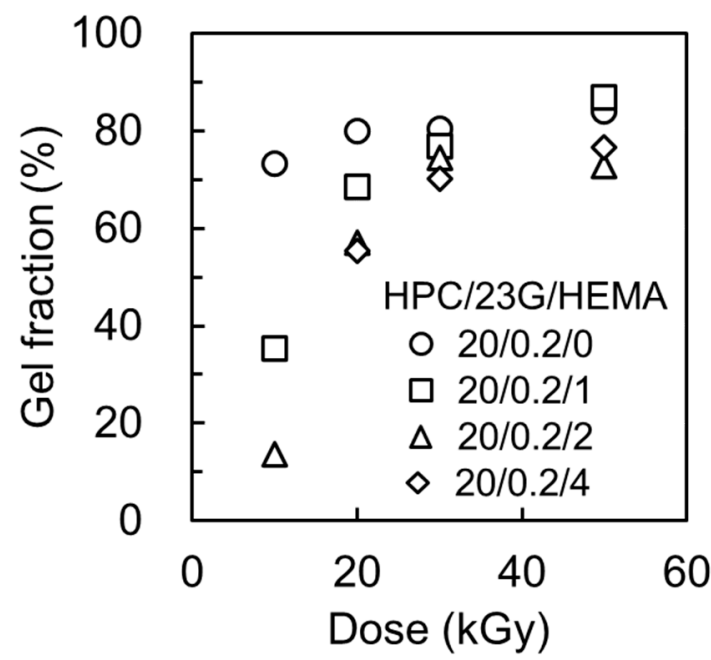

(a)

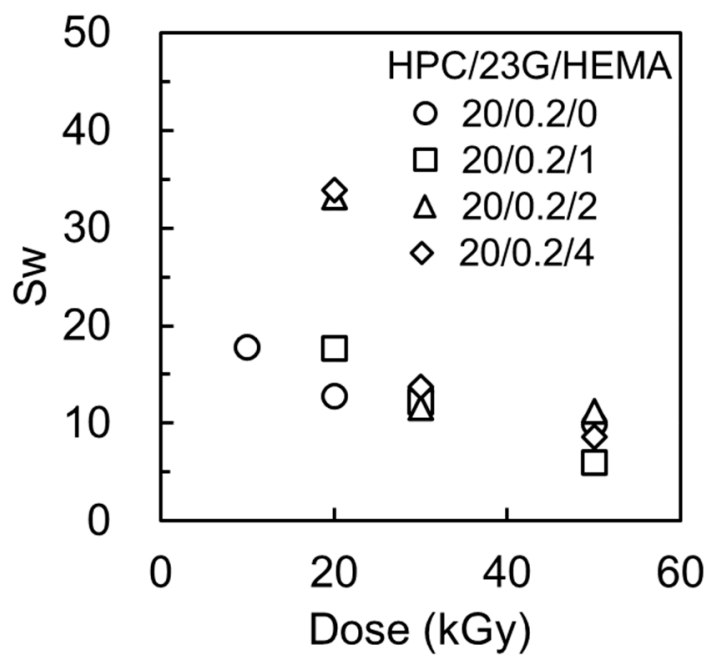

(b)

Figure 6. (a) Gel fraction and (b) Sw of HPC/23G hydrogels as a function of dose. The HPC/23G/HEMA hydrogels were prepared by the irradiation to the mixed aqueous solutions, in which the concentrations of HPC, 23G, HEMA were (○) 20/0.2/0, $\triangle$ ( $20 / 0.2 / 1,(\square) 20 / 0.2 / 2$, and $(\diamond) 20 / 0.2 / 4$ wt. $\%$.

\subsection{Chemical and Physical Analyses}

The chemical structures of the HPC-based hydrogels prepared by the simultaneous reactions of radiation crosslinking and polymerization were analyzed using Fourier transform infrared (FT-IR) spectroscopy. The FT-IR spectra of the hydrogels after washing and drying are shown in Figure 7. The HPC-based hydrogels displayed a prominent peak at $1050 \mathrm{~cm}^{-1}$, which was attributed to C-O asymmetric stretching. The prominent band for confirming the ester on $23 \mathrm{G}$ and HEMA was observed at $1722 \mathrm{~cm}^{-1}$ and was attributed to the stretching vibration of $C=O$. The peak at approximately $1722 \mathrm{~cm}^{-1}$ was also observed in the HPC /23G/HEMA hydrogel, with a low gel fraction obtained at $10 \mathrm{kGy}$. Therefore, this indicated that 23G and HEMA were combined chemically or physically with HPC as the homopolymer and unreacted monomer were removed by washing before the measurement. Although there was almost no peak observed in the HPC /23G hydrogel spectrum, this could be due to the very low concentration of 23G. Clearly, 23G was present in the HPC / 23G hydrogels because both the gel fraction and tensile strength increased compared to the HPC hydrogels prepared without 23G. The transmittances of the HPC/23G and HPC/23G/HEMA hydrogels are shown in Figure 8. Both HPC-based hydrogels were highly transparent and exhibited almost the same transparency as the HPC hydrogel without $23 \mathrm{G}$ and HEMA. 


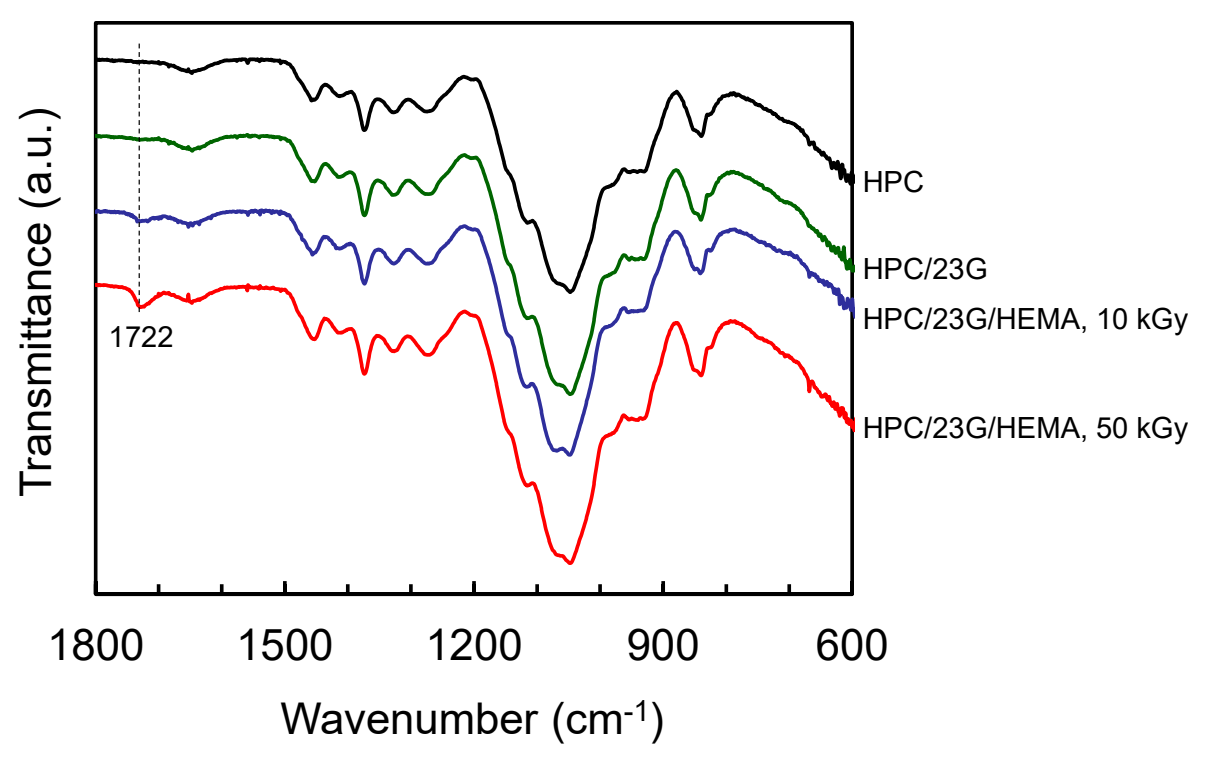

Figure 7. FT-IR ATR spectra of HPC-based hydrogels obtained at the following concentration and dose. HPC (20 wt.\%, $50 \mathrm{kGy}), \mathrm{HPC} / 23 \mathrm{G}$ (20/0.2 wt.\%, $50 \mathrm{kGy})$, and HPC/23G/HEMA (20/0.2/2 wt.\%, $10 \mathrm{kGy}$ and $50 \mathrm{kGy})$.

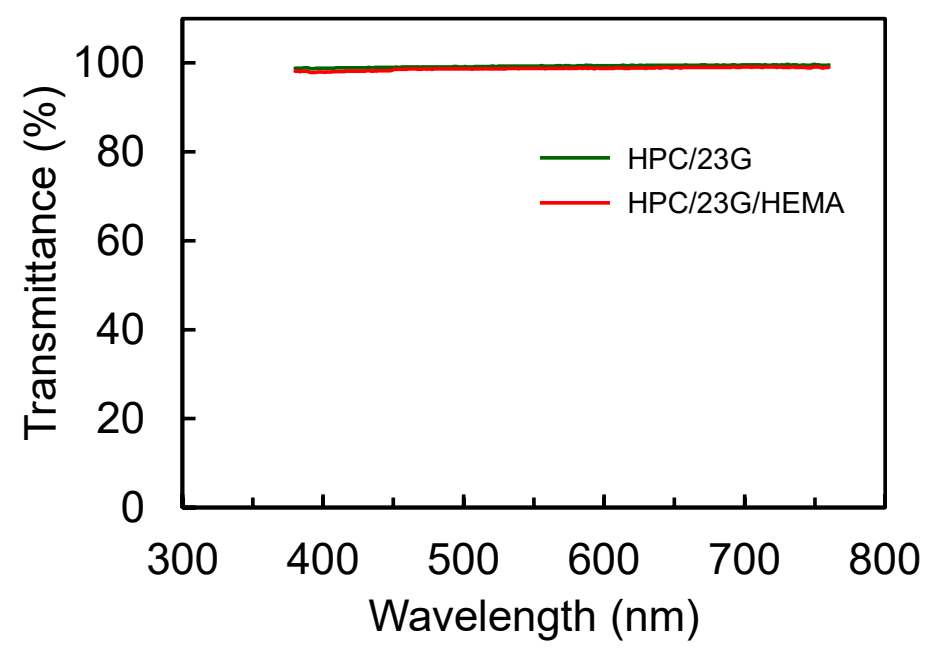

Figure 8. UV-vis spectra of HPC-based hydrogels obtained at the following concentration and dose. HPC/23G (20/0.2 wt.\%, $30 \mathrm{kGy)}$ and HPC/23G/HEMA (20/0.2/2 wt.\%, 50 kGy).

The mechanical properties of HPC-based hydrogels are shown in Figure 9. Young's moduli of HPC-based hydrogels were evaluated and were almost the same at approximately 0.1 MPa. The elasticity of HPC-based hydrogels was comparable to that of a commercially available hydrogel for soft contact lenses [5]. In addition, it is important to have an appropriate balance between the tensile strength and elongation at break because the soft contact lenses are handled manually. The relationship between the tensile strength and elongation at break of the HPC-based hydrogels is shown in Figure 10. As previously described, the tensile strength and elongation at break of the hydrogels were improved by adding 23G to HPC. The elongation at break was further improved by adding HEMA to HPC/23G, which reached $125 \%$. As a result, the HPC/23G/HEMA hydrogel obtained at $50 \mathrm{kGy}$ had a good balance between the tensile strength and the elongation at break, which exhibited a tensile strength of $0.2 \mathrm{MPa}$ and elongation at break of $125 \%$. These values were about 2.0 and 1.8 times compared to the HPC hydrogel without 23G and HEMA, respectively. Therefore, the addition of the crosslinker 23G improved the tensile strength with an increase in the crosslinking density and increased the elongation at 
break by introducing a polyethylene glycol unit with high molecular mobility between the HPC composed of a rigid glucose ring. The introduction of poly (HEMA) in the network polymer increased the mobility of the network polymer, resulting in a further increase in the elongation at break of the hydrogels. The tensile strength of the HEMA-based contact lens materials is reported to be in the range of 0.1-0.6 MPa [30]. The mechanical properties of the HPC /23G/HEMA hydrogel are within the range of those of HEMA-based contact lens materials, so the HPC/23G/HEMA hydrogel could be used as a contact lens material.

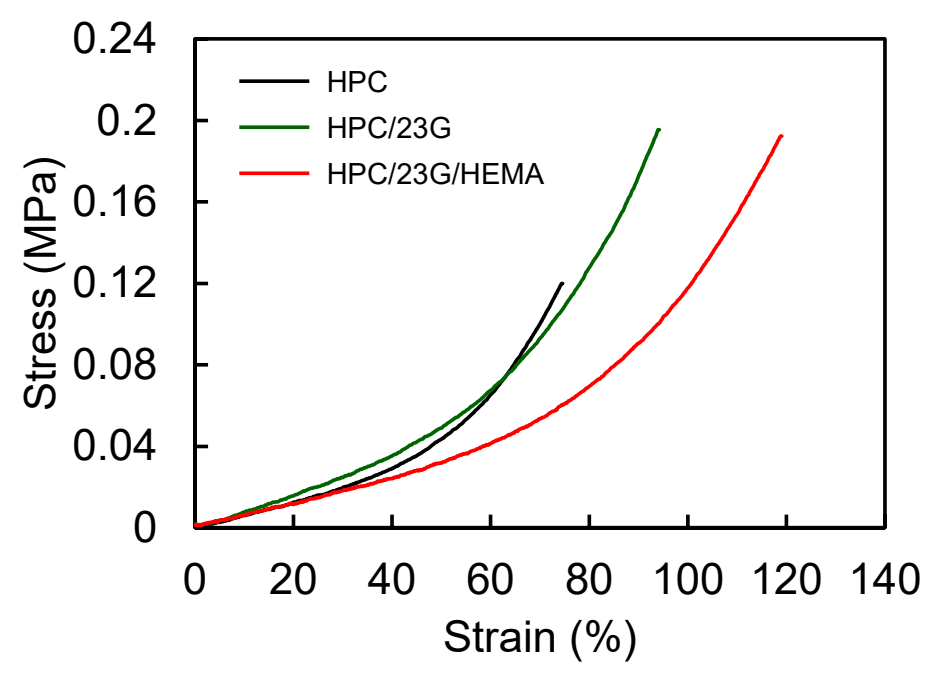

Figure 9. Stress-strain curves of HPC-based hydrogels. The HPC-based hydrogels were prepared at the following concentration and dose: HPC/23G/HEMA = 20/0/0 wt.\%, $50 \mathrm{kGy} ; 20 / 0.2 / 0$ wt. $\%$, $30 \mathrm{kGy} ; 20 / 0.2 / 2$ wt.\%, 50 kGy.

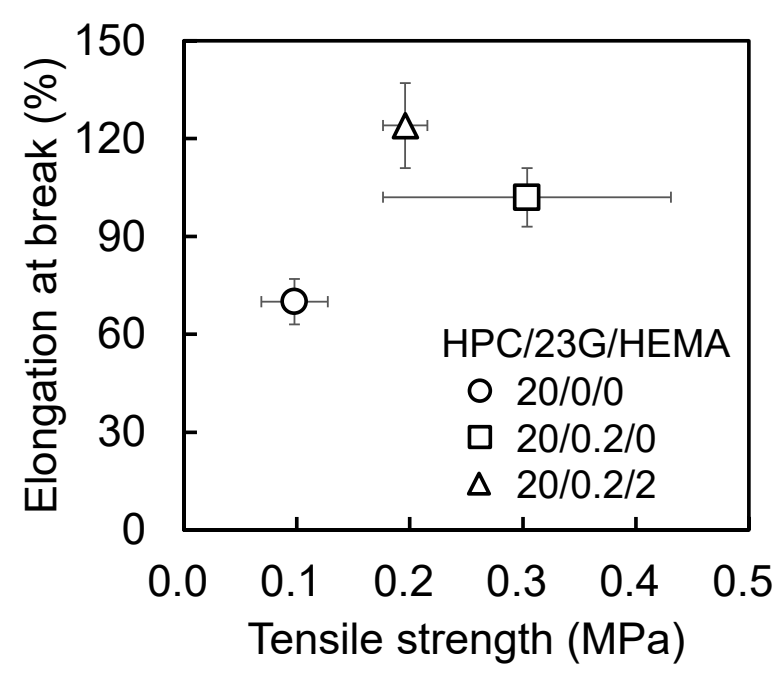

Figure 10. Relationship between tensile strength and elongation at break of HPC-based hydrogels. The HPC-based hydrogels were prepared at the following concentration and dose:

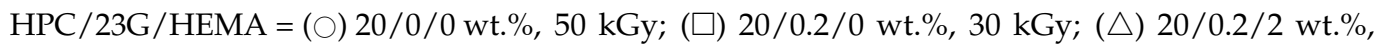
$50 \mathrm{kGy}$.

Cellulose and its derivatives are decomposed in soil under controlled conditions using cellulase [31,32]. The degradation of radiation-crosslinked HPC hydrogels in cellulase solutions has also been reported [33]. The degradation rate is affected by the crosslinking density as well as the degree of substitution on the glucose ring and the size of the substituent [34,35]. In HPC/23G/HEMA hydrogels, cellulase decomposition reaction was inhibited due to the steric hindrance induced by 23G and HEMA. However, the HPC/23G/HEMA hydrogels degraded slowly and steadily. However, HPC hydrogels 
have been reported to exhibit low cell-adsorption properties [36]. Cells and proteins do not easily adhere to the HPC/23G/HEMA hydrogels. Therefore, the HPC/23G/HEMA hydrogels prepared in this study are human- and environmentally friendly soft contact lenses materials because of the low adsorption of protein and higher biodegradability.

\section{Conclusions}

In this study, HPC-based hydrogels were prepared by electron beam irradiation of highly concentrated aqueous solutions containing HPC, 23G, and HEMA. The HPC/23G/HEMA hydrogels prepared by the simultaneous crosslinking of HPC and the polymerization of $23 \mathrm{G}$ and HEMA exhibited appropriate mechanical properties. The tensile strength and elongation at break of the HPC /23G/HEMA hydrogel were approximately 2.0 and 1.8 times larger than the pure HPC hydrogel, respectively. Furthermore, the HPC/23G/HEMA hydrogel could be degraded using cellulase. HPC-based hydrogels with excellent properties may be used to manufacture soft contact lenses as human- and environmentally friendly materials. The HPC-based contact lens may replace conventional soft contact lenses composed of synthetic polymers.

Author Contributions: A.H. and M.T. designed the study. A.H. performed the experiments. A.H. and M.T. wrote the manuscript. All authors also made significant contributions by discussing the results and enhancing the manuscript for intellectual content. All authors have read and agreed to the published version of the manuscript.

Funding: This work was partially supported by JSPS KAKENHI (grant number 17K05134).

Institutional Review Board Statement: Not applicable.

Informed Consent Statement: Not applicable.

Data Availability Statement: The datasets used in the present study are available from the corresponding author upon reasonable request.

Acknowledgments: We thank T. Sato, N. Nagasawa, and M. Tamada for their assistance and discussion.

Conflicts of Interest: The authors declare no conflict of interest.

\section{References}

1. Rolsky, C.; Kelkar, V.P.; Halden, R.U. Nationwide mass inventory and degradation assessment of plastic contact lenses in US wastewater. Environ. Sci. Technol. 2020, 54, 12102-12108. [CrossRef] [PubMed]

2. Wilson, D. Lens waste: Indecent disposal. Opt. Sel. 2018, 182877-1. [CrossRef]

3. Musgrave, C.S.; Fang, F. Contact lens materials: A materials science perspective. Materials 2019, 12, 261. [CrossRef] [PubMed]

4. Zare, M.; Bigham, A.; Zare, M.; Luo, H.; Rezvani Ghomi, E.; Ramakrishna, S. pHEMA: An overview for biomedical applications. Int. J. Mol. Sci. 2021, 22, 6376. [CrossRef] [PubMed]

5. Bhamra, T.S.; Tighe, B.J. Mechanical properties of contact lenses: The contribution of measurement techniqes and clinical feedback to 50 years of materials development. Contact Lens Anterior Eye 2017, 40, 70-81. [CrossRef] [PubMed]

6. Moradi, O.; Modarress, H.; Norouzi, M. The effects of concentration, $\mathrm{pH}$, and ionic strength on lysozyme adsorption onto AA and HEMA contact lenses. Iran. Polym. J. 2003, 12, 477-484.

7. Heynen, M.; Ng, A.; Martell, E.; Subbaraman, L.N.; Jones, L. Activity of deposited lysozyme on contemporary soft contact lenses exposed to differing lens care systems. Clin. Ophthalmol. 2021, 15, 1727-1733. [CrossRef]

8. Garrett, Q.; Garrett, R.W.; Milthorpe, B.K. Lysozyme sorption in hydrogel contact lenses. Investig. Ophthalmol. Vis. Sci. 1999, 40, 897-903.

9. Guo, H.; Uehara, Y.; Matsuda, T.; Kiyama, R.; Li, L.; Ahmed, J.; Katsuyama, Y.; Nonoyama, T.; Kurokawa, T. Surface charge dominated protein absorption on hydrogels. Soft Matter 2020, 16, 1897-1907. [CrossRef]

10. Greene, J. Biodegradation of compostable plastics in green yard-waste compost environment. J. Polym. Environ. 2007, 15, 269-273. [CrossRef]

11. Fei, B.; Wach, R.A.; Mitomo, H.; Yoshii, F.; Kume, T. Hydrogel of biodegradable cellulose derivatives. I. Radiation-induced crosslinking of CMC. J. Appl. Polym. Sci. 2000, 78, 278-283. [CrossRef]

12. Wang, M.; Xu, L.; Hu, H.; Zhai, M.; Peng, J.; Nho, Y.; Li, J.; Wei, G. Radiation synthesis of PVP/CMC hydrogels as wound dressing. Nucl. Instrum. Methods Phys. Res. B 2007, 265, 385-389. [CrossRef]

13. Nizam El-Din, H.M.; Abd Alla, S.G.; El-Naggar, A.W.M. Swelling and drug release properties of acrylamide/carboxymethyl cellulose networks formed by gamma irradiation. Radiat. Phys. Chem. 2010, 79, 725-730. [CrossRef] 
14. Oyama, T.G.; Oyama, K.; Kimura, A.; Yoshida, F.; Ishida, R.; Yamazaki, M.; Miyoshi, H.; Taguchi, M. Collagen hydrogels with controllable combined cues of elasticity and topography to regulate cellular processes. Biomed. Mater. 2021, 16, 045037. [CrossRef]

15. Kimura, A.; Jo, J.; Yoshida, F.; Hong, Z.; Tabata, Y.; Sumiyoshi, A.; Taguchi, M.; Aoki, I. Ultra-small size gelatin nanogel as a blood brain barrier impermeable contrast agent for magnetic resonance imaging. Acta Biomater. 2021, 125, 290-299. [CrossRef]

16. Oyama, T.G.; Oyama, K.; Miyoshi, H.; Taguchi, M. 3D cell sheets formed via cell-driven buckling-delamination of patterned thin films. Mater. Des. 2021, 208, 109975. [CrossRef]

17. Barba, B.J.D.; Oyama, T.G.; Taguchi, M. Simple fabrication of gelatin-polyvinyl alcohol bilayer hydrogel with wound dressing and nonadhesive duality. Polym. Adv. Technol. 2021. [CrossRef]

18. Zainal, S.; Mohd, N.; Suhaili, N.; Anuar, F.; Mat Lazim, A.; Othaman, R. Preparation of cellulose-based hydrogel: A review. J. Mater. Res. Technol. 2021, 10, 935-952. [CrossRef]

19. Wach, R.A.; Mitomo, H.; Nagasawa, N.; Yoshii, F. Radiation crosslinking of carboxymethylcellulose of various degree of substitution at high concentration in aqueous solutions of natural pH. Radiat. Phys. Chem. 2003, 68, 771-779. [CrossRef]

20. Fekete, T.; Borsa, J.; Takács, E.; Wojnárovits, L. Synthesis of cellulose-based superabsorbent hydrogels by high-energy irradiation in the presence of crosslinking agent. Radiat. Phys. Chem. 2016, 118, 114-119. [CrossRef]

21. Liu, P.; Zhai, M.; Li, J.; Peng, J.; Wu, J. Radiation preparation and swelling behavior of sodium carboxymethyl cellulose hydrogels. Radiat. Phys. Chem. 2002, 63, 525-528. [CrossRef]

22. Hiroki, A.; Yamashita, S.; Sato, Y.; Nagasawa, N.; Taguchi, M. New polymer gel dosimeters consisting of less toxic monomers with radiation-crosslinked gel matrix. J. Phys. Conf. Ser. 2013, 444, 012028. [CrossRef]

23. Hiroki, A.; Yamashita, S.; Kimura, A.; Nagasawa, N.; Taguchi, M. Effect of heavy ion irradiation on optical property of radiationcrosslinked hydroxypropyl cellulose gel containing methacrylate monomers. Nucl. Instrum. Methods Phys. Res. B 2015, 365, 583-586. [CrossRef]

24. Hiroki, A.; Tran, H.T.; Nagasawa, N.; Yagi, T.; Tamada, M. Metal adsorption of carboxymethyl cellulose/carboxymethyl chitosan blend hydrogels prepared by Gamma irradiation. Radiat. Phys. Chem. 2009, 78, 1076-1080. [CrossRef]

25. Gong, J.P.; Katsuyama, Y.; Kurokawa, T.; Osada, Y. Double-network hydrogels with extremely high mechanical strength. Adv. Mater. 2003, 15, 1155-1158. [CrossRef]

26. Haraguchi, K.; Takehisa, T. Nanocomposite hydrogels: A unique organic-inorganic network structure with extraordinary mechanical, optical, and swelling/de-swelling properties. Adv. Mater. 2002, 14, 1120-1124. [CrossRef]

27. Hiroki, A.; Hong, P.T.T.; Nagasawa, N.; Tamada, M. Biodegradability of blend hydrogels based on carboxymethyl cellulose and carboxymethyl starch. Trans. Mat. Res. Soc. Jpn. 2011, 36, 397-400. [CrossRef]

28. Yoshii, F.; Zhanshan, Y.; Isobe, K.; Shinozaki, K.; Makuuchi, K. Electron beam crosslinked PEO and PEO/PVA hydrogels for wound dressing. Radiat. Phys. Chem. 1999, 55, 133-138. [CrossRef]

29. Wach, R.A.; Mitomo, H.; Yoshii, F. ESR investigation on gamma-irradiated methylcellulose and hydroxyethylcellulose in dry state and in aqueous solution. J. Radioanal. Nucl. Chem. 2004, 261, 113-118. [CrossRef]

30. Tranoudis, I.; Efron, N. Tensile properties of soft contact lens materials. Contact Lens Anterior Eye 2004, 27, 177-191. [CrossRef]

31. Kumakura, M.; Kaetsu, I. Radiation-induced decomposition and enzymatic hydrolysis of cellulose. Biotech. Bioeng. 1978, 20, 1309-1315. [CrossRef]

32. Simon, J.; Müller, H.P.; Koch, R.; Müller, V. Thermoplastic and biodegradable polymers of cellulose. Polym. Degrad. Stab. 1998, 59, 107-115. [CrossRef]

33. Wach, R.A.; Mitomo, H.; Yoshii, F.; Kume, T. Hydrogel of radiation-induced cross-linked hydroxypropylcellulose. Macromol. Mater. Eng. 2002, 287, 285-295. [CrossRef]

34. Reese, E.T. Biological degradation of cellulose derivatives. Ind. Eng. Chem. 1957, 49, 89-93. [CrossRef]

35. Pekel, N.; Yoshii, F.; Kume, T.; Güven, O. Radiation crosslinking of biodegradable hydroxypropylmethylcellulose. Carbohydr. Polym. 2004, 55, 139-147. [CrossRef]

36. Nagasawa, N.; Kimura, A.; Idesaki, A.; Yamada, N.; Koka, M.; Satoh, T.; Ishii, Y.; Taguchi, M. Microfabrication of biocompatible hydrogels by proton beam writing. Nucl. Instrum. Methods Phys. Res. B 2017, 409, 102-106. [CrossRef] 